\title{
ECOLOGIA POLIIIICA COMO ETNOGRAFIA: UM GUIA TEÓRICO E METODOLÓGICO
}

\author{
Paul Elliot Little \\ Universidade de Brasília - Brasil
}

Resumo: Algumas das mais importantes transformações recentes no paradigma ecológico são a elaboração de sínteses transdisciplinares entre as ciências sociais e naturais, a proposta heurística da simetria epistemológica e o diálogo metodológico com os estudos da complexidade. Essas transformações servem como base para discutir os aportes da antropologia ao novo campo de pesquisa da ecologia política. Após a delimitação do subcampo da "etnografia dos conflitos socioambientais", as práticas específicas da etnografia multiator, que identifica e diferencia os agentes sociais e os "agentes naturais", e do uso de múltiplos níveis espaciais e temporais de análise são delineadas. $O$ artigo termina com uma breve discussão dos usos acadêmicos, críticos e públicos da ecologia política.

Palavras-chave: análise fractal, conflitos socioambientais, ecologia política, etnografia.

\begin{abstract}
Some of the most important recent transformations in the ecological paradigm are the development of transdisciplinary syntheses between the social and natural sciences, the heuristic proposal of epistemological symmetry and the methodological dialogue with complexity studies. These transformations form the groundwork for a discussion of the contributions of anthropology to the new field of study of political ecology. After the delimitation of the sub-field of the "ethnography of socioenvironmental conflicts," the specific practices of multi-actor ethnography, which identifies and differentiates between social and natural agents, and of the use of multiple spatial and temporal levels of analysis are delineated. The article ends with a brief discussion of the academic, critical and policy implications of political ecology research.
\end{abstract}

Keywords: ethnography, fractal analysis, political ecology, socioenvironmental conflicts. 


\section{Introduç̃o}

Nos últimos 20 anos, a “ecologia política” emergiu como um novo campo de pesquisa que combina o foco da ecologia humana nas inter-relações que sociedades humanas mantêm com seus respectivos ambientes biofísicos com conceitos da economia política que analisa as relações estruturais de poder entre essas sociedades (Little 1999a; Sheridan, 1988; Stonich 1993). Esse campo é fruto de um diálogo intenso entre as disciplinas da biologia, da antropologia, da geografia, da história e da ciência política, criando um espaço transdisciplinar próprio dentro das ciências naturais e sociais. Na contramão de muita da literatura sobre transdisciplinaridade, afirmo que esse espaço não elimina as diferenças entre as distintas disciplinas e pode, até, realçá-las. Cada matriz disciplinar emprega seus conceitos e técnicas dentro do campo da ecologia política na procura de iluminar diferentes aspectos das relações ecológicas frente a novas realidades.

Este artigo tem a finalidade de mapear alguns dos aportes conceituais e metodológicos que a antropologia, e mais especificamente a etnografia, oferece à ecologia política. Apesar dessa ênfase na etnografia, não apresentarei material etnográfico aqui, já que restringirei a análise ao âmbito expressamente teórico e metodológico. Para análises etnográficas dentro de uma abordagem da ecologia política, refiro ao leitor vários de meus trabalhos anteriores (Little, 1992, 1999b, 2001, 2006).

\section{Politizando e complexificando a abordagem ecológica}

\section{As múltiplas ramificacões do paradigma ecológico}

A palavra “ecologia” foi usada pela primeira vez em 1858 pelo naturalista norte-americano Henry David Thoreau, e ganhou uma acepção propriamente científica pelo biólogo alemão Ernst Haeckel em 1866. Desde então, a ecologia experimentou um duplo e simultâneo desenvolvimento: um dentro da sociedade civil como movimento social ecologista e outro dentro da academia como disciplina científica (Bramwell, 1989). O nosso interesse neste artigo fica restrito a esse segundo desenvolvimento.

No início do século XX a ecologia se consolidou como uma subdisciplina da biologia, conhecida como a “ecologia natural”. A partir da década de 1930, 
funda-se a "ecologia humana”, que aplica os métodos da ecologia natural para as sociedades humanas (Hawley, 1950). Nessa mesma época, o antropólogo Julian Steward começa a analisar as dimensões culturais das adaptações ecológicas de grupos indígenas (Steward, 1938) para posteriormente codificar essa linha de pesquisa no campo da "ecologia cultural” (Steward, 1955). A ecologia cultural produziu várias ramificações dentro da antropologia, nas quais se destacam a etnoecologia (Conklin, 1954), a ecologia neofuncionalista (Rappaport, 1968), a ecologia humana (Moran, 1990), a ecologia processual (Bennett, 1993), a ecologia espiritual (Kinsley, 1995) e, o que é nosso interesse principal aqui, a ecologia política (Schmink; Wood, 1987). ${ }^{1}$

Essas múltiplas ramificações do paradigma ecológico atestam uma constante ampliação de seu escopo de estudo, ao mesmo tempo em que representam respostas da ciência ecológica para as novas realidades políticas e ambientais que as sociedades confrontam hoje. Duas das mais importantes forças contemporâneas são a vertiginosa aceleração, no último meio século, do processo da globalização e a crescente gravidade da crise ambiental no plano mundial. A atual fase de globalização acontece no âmbito da expansão do sistema capitalista, sob a égide da ideologia neoliberal e de situações de neocolonialismo político e neoimperialismo cultural. Quanto à crise ambiental, além dos problemas propriamente planetários, como o aquecimento da atmosfera, o crescimento do buraco na camada de ozônio e as mudanças nas correntes oceânicas, no plano regional existem recorrentes crises ambientais manifestas pela desertificação, inundações, esgotamento de recursos naturais, contaminação do ar, água e solo, modificações climáticas e perda de biodiversidade.

É justamente dentro dessa conjuntura que devemos entender a emergência da ecologia política como campo de pesquisa. É necessário ressaltar que a ecologia política não pretende "suplantar" nem "superar" as outras ramificações da ecologia acima mencionadas. Cada ramificação produz conhecimentos e oferece insights próprios que podem servir para entender distintas dimensões da realidade socioambiental. A introdução da economia política dentro do paradigma ecológico, porém, teve o impacto singular de colocar à vista os choques entre sistemas produtivos, e assim detalhar melhor os vínculos entre as mudanças econômicas e a crise ambiental.

\footnotetext{
1 Cada uma dessas ramificações conta com uma literatura extensa. As poucas referências apresentadas aqui representam textos fundadores ou paradigmáticos.
}

Horizontes Antropológicos, Porto Alegre, ano 12, n. 25, p. 85-103, jan./jun. 2006 
Nesse quadro maior, a antropologia ajuda na análise dos modos culturalmente específicos de adaptação ecológica de distintos grupos sociais - os sistemas produtivos e tecnologias que empregam, os recursos naturais que exploram e as ideologias que utilizam para justificar seu modo de adaptação e as reivindicações territoriais que defendem - e da interação dinâmica e conflituosa provocada pelo choque entre esses modos de adaptação. $\mathrm{O}$ foco nos grupos sociais invariavelmente levanta o tema das práticas ambientais em conflito de tal forma que a análise dos chamados "conflitos socioambientais" se tornou um elemento central da ecologia política. A análise desses conflitos não fica restrita ao comportamento dos estoques dos recursos naturais e tenta responder a perguntas como: quem usa os recursos? quando? por quais razões? a que preço? com quais impactos?

\section{Cruzando a divisa entre a natureza e a cultura}

A pesquisa ecológica trabalha em ambos os lados da divisa entre o mundo biofísico (“a natureza”) e o mundo social (“a cultura”). Essa tarefa é particularmente difícil devido à grande separação, tanto epistemológica quanto institucional, entre as ciências naturais e as ciências sociais. Se as ciências sociais confrontam o desafio de incorporar as dinâmicas do mundo biofísico dentro de sua prática, as ciências naturais enfrentam o desafio inverso: no seu entendimento dos distintos ciclos naturais teria que levar em conta o mundo humano e suas estruturas políticas e socioeconômicas. Para que existisse uma ciência verdadeiramente ecológica, um diálogo profundo entre as ciências sociais e as ciências naturais, que focaliza o relacionamento dinâmico e interdependente entre o mundo biofísico e o mundo social, é necessário. Isso, por sua vez, requer certas mudanças paradigmáticas na prática científica nos planos epistemológico, metodológico e institucional.

Uma das saídas a essa dificuldade consiste na proposta de eliminar de vez a distinção entre natureza e cultura. Haraway (1992, p. 42) propõe o conceito de "ciborgos", que define como "compostos do orgânico, do técnico, do mítico, do textual e do político”; Latour (2004, p. 373) cunha o conceito de “coletivo”, que define como "um procedimento para coligar as associações de humanos e não-humanos”; Rabinow (1992) argumenta que estamos entrando na época da "biossocialidade” na qual a natureza se tornará artificial enquanto a cultura se tornará natural. Apesar da importância dessa linha conceitual e das suas implicações para as práticas de pesquisa, considero que sua radicalidade esconde 
uma dose, forte demais, de hubris antropocêntrico na medida em que postula que os seres humanos somos tão potentes, e tão onipresentes, que já deixamos a nossa marca em todo do mundo biofísico, o que é um claro exagero. O Sol, a força gravitacional, as forças eletromagnéticas, os buracos negros, a via Láctea, só para citar alguns, podem existir muito bem sem os seres humanos e, portanto, não são nem ciborgos, nem coletivos, nem vivem na época da biossocialidade.

Outra saída a esse impasse, que considero mais frutífera, é a elaboração de sínteses transdisciplinares. Goodman e Leatherman (1998), por exemplo, delineiam os contornos de uma "nova síntese biocultural”, na qual os aportes de disciplinas localizadas em ambos os lados da divisa natureza/cultura são analisados dentro de um marco teórico unificado. Dentro da teoria ecológica propriamente dita, Holling e Sanderson (1996) reconhecem as dinâmicas diferenciadas entre os sistemas naturais e sociais e, a partir daí, constroem modelos da dinâmica ecológica que surgem das interfaces entre os dois tipos de sistemas veja também Bateson (1972).

A construção de um paradigma ecológico que incorpore essas sínteses apresenta um conjunto de desafios heurísticos que requerem outros procedimentos explicativos. A noção de "simetria epistemológica" postula que as causas de um fenômeno determinado podem proceder tanto do mundo social quanto do mundo natural (Barnes; Bloor, 1982). Em muitos casos, os cientistas sociais só procuram causas sociais e ignoram as causas biofísicas. Vayda e Walters (1999) fazem uma crítica a muita da produção em ecologia política que privilegia a priori a dimensão política a custo de outras dimensões presentes, particularmente as dinâmicas biofísicas. Na implementação analítica dessa simetria, os cientistas sociais vêm usando o conceito de "agente natural", no qual as forças da natureza são consideradas como uma espécie de ator, no sentido de que "agem" sobre uma realidade determinada, mas que difere qualitativamente dos atores sociais, já que não têm "vontade" nem "intencionalidade”. Como ambos os tipos de atores são tratados com o potencial de influir na construção de uma paisagem determinada, segue o princípio de simetria epistemológica. Law (1987, p. 114), num estudo histórico, afirma que para explicar adequadamente os desenvolvimentos tecnológicos da navegação portuguesa do século XVI, foi necessário "tratar os adversários naturais e sociais nos termos de um vocabulário analítico comum”.

Os cientistas naturais, por sua parte, que tendem a lidar exclusivamente com causas biofísicas, também precisam de novos conceitos que lhes permi- 
tam incorporar a ação antrópica como elemento integral nas suas análises. Para tanto, o pesquisador em ecologia política deve mapear as principais forças biofísicas, tais como a conformação geológica de uma região, a evolução biológica da fauna e flora e os fluxos hídricos, junto com as principais atividades humanas, tais como os sistemas agrícolas, os efluentes industriais lançados ao ambiente e a infra-estrutura de transporte e comunicação instalada na região. Além de estar atento aos dois lados dessa causalidade, o pesquisador também procura identificar as realidades socioambientais que surgem das interações entre os mundos biofísico e social que só uma abordagem ecológica é preparada para enxergar.

\section{A transdisciplinaridade da ecologia}

Muita pesquisa em ecologia política trata diretamente de problemas específicos, sejam eles ambientais, territoriais ou da saúde. Esses problemas se expressam mediante múltiplas esferas de interação, cada uma das quais tem suas próprias regras e normas de funcionamento. Quando pensamos, por exemplo, em interações virais estamos, aparentemente, dentro da esfera da epidemiologia. Mas quando procuramos entender uma pandemia mundial como a Aids, temos que entender também as condutas sexuais (esfera da sexualidade), os fluxos migratórios (esfera demográfica), as inter-relações psíquicas (esfera psicológica), as forças do mercado (esfera econômica) e os avanços imunológicos (esfera médica), só para mencionar alguns. As ciências ecológicas sempre estão lidando com distintas esferas de interação, o que demanda uma abordagem transdisciplinar. Por isso, a ecologia política incorpora conceitos, métodos e enfoques de disciplinas tão diversas como a antropologia, a ecologia humana, a geografia, a medicina, a economia política, a botânica e a história.

Há inúmeras maneiras de conjugar as disciplinas científicas, o que cria distintas configurações transdisciplinares. Qual é a configuração transdisciplinar da ecologia? Uma orientação básica consiste na noção de “holismo”, entendida como uma abordagem que "prioriza o entendimento integral dos fenômenos, em oposição ao procedimento analítico que em que seus componentes são tomados isoladamente" (Dicionário Eletrônico Houaiss, 2004). Dada a complexidade dos fenômenos sob análise, o holismo é extremamente difícil (senão impossível) de se realizar completamente. De fato, é difícil sair totalmente do reducionismo, sendo que toda pesquisa ecológica precisa de algum tipo de re- 
corte geográfico e temático. Ao mesmo tempo, o holismo não deve ser visto como um convite para realizar o que Haraway (1988) nomeia o "truque de Deus”, onde se pretende apresentar uma visão onipresente da realidade que somente Deus teria.

Localizo três princípios que fazem parte do núcleo duro do paradigma ecológico, sendo que a aplicação específica de cada princípio varia segundo o tema e o lugar sob pesquisa: 1) o foco central da pesquisa ecológica são sempre relações - sociais, naturais ou socioambientais - e não objetos substantivos. Conceitos como cadeias tróficas, conflitos territoriais, fluxos de energia, choque de valores e homeostase, por exemplo, precisam ser entendidos em forma relacional; 2) o uso de análises contextualistas que colocam as relações dentro seus respectivos marcos históricos e ambientais representa um segundo princípio. Os conceitos de nicho ou de adaptação, que são importantes para a análise ecológica, somente têm sentido quando se sabe o contexto específico no qual os fluxos e as relações acontecem; 3) a ecologia utiliza metodologias processuais onde o acompanhamento dos fluxos (de energia; de pessoas; de sementes; de idéias; de pólen; etc.) e a identificação de sua dinâmica interna é uma parte essencial da pesquisa. Os conceitos da dialética, da estocástica, da dinamicidade e da evolução expressam essa dimensão processual. O uso desses três princípios fez o paradigma ecológico se aproximar, nas últimas duas décadas, ao campo de pesquisa conhecido como os "estudos da complexidade" (Kauffman, 1991; Waldrop, 1992). Acredito que um diálogo entre a ecológica política e o paradigma da complexidade pode frear quaisquer tendências para um relapso ao reducionismo na teoria ecológica.

\section{A etnografia dos conflitos socioambientais}

\section{Definição e delimitacão antropológica do conflito}

Vimos como a análise dos conflitos socioambientais é uma parte quase intrínseca de uma abordagem da ecologia política. Conflitos socioambientais referem-se a um conjunto complexo de embates entre grupos sociais em função de seus distintos modos de inter-relacionamento ecológico.

Um conceito propriamente antropológico do conflito vai além de um foco restrito nos embates políticos e econômicos para incorporar elementos cosmológicos, rituais, identitários e morais que não sempre são claramente visí- 
veis desde a ótica de outras disciplinas. Um olhar antropológico pode enxergar conflitos latentes que ainda não se manifestaram politicamente no espaço público formal, porque os grupos sociais envolvidos são politicamente marginalizados ou mesmo invisíveis ao olhar do Estado. Como os antropólogos trabalham diretamente com muitos desses grupos - povos indígenas; quilombolas; agroextrativistas; ribeirinhos; favelados - a etnografia dos conflitos socioambientais explicita as bases latentes dos conflitos e da visibilidade a esses grupos marginalizados. Nesse sentido, o uso de uma metodologia etnográfica representa um aporte significativo da antropologia à ecologia política.

Ao colocar o conflito em si como o foco central da etnografia, e não um grupo social em particular, o antropólogo é obrigado a identificar os distintos atores sociais e recursos ambientais envolvidos no conflito, analisar esses atores em interação entre si, com seu meio biofísico e com seu meio social e levantar as reivindicações de cada grupo e suas respectivas cotas de poder formal e informal. O mapeamento das interações políticas ajuda ao pesquisador a entender a dinâmica própria de cada conflito. Um conflito pode vacilar durante anos entre os estágios latente e manifesto: pode haver momentos do conflito ficar muito "quente" e depois perder sua visibilidade, para posteriormente "esquentar" de novo.

O entendimento da dinâmica interna do conflito inclui a identificação das polarizações das posições e o mapeamento das alianças e coalizões, sempre sob a observação que, durante o longo percurso do conflito, as posições dos distintos grupos podem mudar de tal forma que antigos aliados se transformam em inimigos ou vice-versa. O etnógrafo também deve analisar as variadas táticas e estratégias utilizadas pelos grupos sociais e perfilar as distintas tentativas de resolução. Dessa forma, a etnografia dos conflitos sociais se insere plenamente no paradigma ecológico: tem foco nas relações; usa uma metodologia processual; e contextualiza o conhecimento produzido.

\section{Etnografia multiator}

A etnografia dos conflitos socioambientais difere da etnografia tradicional em vários aspectos essenciais. Primeiro, o foco da etnografia não é o modo de vida de um grupo social, mas tem como seu objeto principal a análise dos conflitos socioambientais em si e as múltiplas interações sociais e naturais que os fundamentam. Segundo, não trata de um único grupo social, mas tem que lidar simultaneamente com vários grupos sociais. Terceiro, o escopo geográfico é 
rara vez limitado ao âmbito local do grupo, já que incorpora vários níveis de articulação social. Finalmente, enquanto etnografias tradicionais dedicavam um capítulo ao habitat natural do grupo, na etnografia dos conflitos socioambientais o ambiente biofísico se torna um elemento crucial em quase todos os assuntos a serem tratados.

Uma das primeiras tarefas que o etnógrafo confronta é a identificação e análise dos principais atores sociais envolvidos no conflito, tarefa que se complica quando o número desses atores é alto. Além de incorporar os grupos sociais marginalizados, a etnografia multiator deve apresentar os atores sociais "fantasmagóricos" que não estão presentes fisicamente no sítio do conflito, mas que exercem uma influência nele à distância (Giddens, 1990). Esse tipo de etnografia nunca seria exaustivo, já que o etnógrafo deve dar uma espécie de “tratamento igualitário" para múltiplos grupos, o que reduz a profundidade de cada um desses tratamentos (Bennett, 1969). Mais uma vez, a meta não é etnografia descritiva em si, mas o estudo de conflitos e inter-relações específicos por meio do método etnográfico.

Outro elemento fundamental nesse tipo de etnografia é a identificação dos interesses e reivindicações em torno dos recursos naturais e do território, seguido por um levantamento das interações entre cada um dos atores sociais dentro da arena política. O etnógrafo deve identificar também os distintos discursos em choque e suas respectivas bases de legitimidade cultural e política, sejam elas explícitas ou implícitas. Um passo seguinte consiste na análise dos atores sociais e na descrição das suas distintas cotas de poder. Em muitos casos, o exercício do poder não acontece em arenas formais, obrigando o pesquisador a descobrir os jogos ocultos de poder, seja nos arquivos oficiais do Estado, como ocorre nos casos de grilagem de terras, seja na escuridão da noite num acampamento rural, como em casos de assassinatos por jagunços.

Essas tarefas de pesquisa requerem que o etnógrafo ganhe acesso e estabeleça um diálogo com todos os principais atores sociais do conflito (isto é, tanto com os "bandidos” da história quanto os “mocinhos”). Para tanto, o etnógrafo precisa ter uma dose mínima de empatia com os atores sociais, mesmo aqueles de que não gosta pessoalmente (sejam eles garimpeiros, traficantes, fazendeiros, petroleiros, oligarcas, etc.), já que é quase impossível escrever boa etnografia sobre grupos que se detesta. O esforço de dialogar com membros de distintos grupos sociais e entender seus respectivos pontos de vista demanda um certo grau de suspensão de valores por parte do etnógrafo, ao mesmo tempo em que evite apoiar explicitamente um dos lados em conflito. 


\section{A ctnografia da "agência natural"}

As forças biofísicas envolvidas no conflito, com particular ênfase nos recursos naturais, representam muito mais que o mero contexto em que as forças sociais atuam. As forças biofísicas operam segundo suas próprias dinâmicas internas, as quais constantemente modificam as relações ecológicas em disputa. Em recentes trabalhos, historiadores ambientais propõem que fenômenos tais como o esgotamento de recursos naturais, secas prolongadas, grandes incêndios florestais, desertificação e pandemias podem ser entendidos como uma espécie de "agência” do mundo biofísico, porém radicalmente diferente da "agência social” (Dean, 1995; Merchant, 1989; Worster, 1993).

Em conflitos socioambientais, a agência humana e natural deve ser analisada na sua interação para compreender melhor a dinâmica do conflito. Essa interação não funciona segundo um determinismo ambiental - veja Roosevelt (1991) e Diamond (1997), por visões opostas-, mas via relacionamentos constantes de dupla via entre as agências natural e social (Levins; Lewontin, 1985). Quando as forças biofísicas são entendidas como um tipo de agência nãosocial, conceitos sociais como soberania e autonomia, por exemplo, precisam ser reformulados (Kuehls, 1996). Se um grupo social não mantém o poder (ou o conhecimento) para "conter” ou "controlar” a ação das forças biofísicas dentro de seu território, a soberania e a autonomia desse grupo são colocadas em xeque.

A agência natural deve ser entendida como múltipla em caráter, sendo muitos tipos de agência de muitos agentes naturais, e não como uma agência homogênea de uma natureza genérica. A agência de um gorila, que pode ser explicada por um primatólogo, é radicalmente diferente da agência de um vulcão, que um vulcanólogo pode analisar melhor. Recentes análises etnográficas incorporam agentes naturais como a corrente oceânica El Niño (Meltzoff; Lichtensztajn, 1999) e furações (Emanuel; Greenberg, 1999) como uma parte integral da dinâmica socioambiental.

\section{Os niveis espaciais fractais}

Durante seu primeiro século de existência como disciplina acadêmica, a antropologia se especializou no estudo de fenômenos locais mediante ricos e densos trabalhos etnográficos em sociedades de pequena escala. Com a ampli- 
ação do escopo da antropologia para o estudo de sociedades camponesas, bairros metropolitanos e, posteriormente, processos de globalização, o método etnográfico confrontou (e continua confrontando) o desafio de elaborar novas ferramentas analíticas e técnicas. O estudo das lutas contemporâneas planetárias sobre os recursos naturais, como a ecologia política propõe fazer, aumenta a importância de incorporar outros níveis de articulação e análise (Bennett, 1976) e entender melhor os chamados "povos da biosfera" (Dasmann, 1988) com seus impactos socioambientais inéditos.

Um ator social pode funcionar nos níveis de articulação local, regional, nacional ou global. Em geral, cada ator social tem um nível específico que serve como seu principal nível de funcionamento e eficácia política. Uma empresa transnacional, por exemplo, pode ser muito eficaz no plano global, mas não conseguir implantar suas metas produtivas no plano local. Uma comunidade indígena, para tomar outro exemplo, pode ter uma presença política significativa numa federação étnica regional, mas não ter muita expressividade no plano nacional.

O nível principal de articulação, por sua vez, serve como base para a descrição das relações que mantém com atores funcionando nos níveis superior e inferior. Quando utilizadas estrategicamente, essas "relações transníveis" podem ser uma fonte de poder para os atores sociais. Grupos locais podem conseguir apoio de atores sociais funcionando nos níveis regional, nacional ou internacional para promover seus interesses específicos mediante ações tais como a aplicação de pressão política, o lançamento de uma campanha na mídia ou a cessão de financiamento para obras de infra-estrutura.

A mobilização de atores sociais localizados em outros níveis rara vez acontece de forma mecânica, mas tende a ser volátil e irregular, já que depende da conjuntura política e social, da proximidade e intensidade das relações e do tema específico sendo tratado (Ribeiro; Little, 1998). Atores sociais locais podem "pular” níveis ao convocar atores sociais operando no nível internacional que têm interesses afins e assim circundar atores sociais regionais ou nacionais hostis. A análise dessa teia de relações vai muito além de uma "contextualização" para demonstrar como essas conexões transníveis são estabelecidas, cultivadas e acionadas em momentos diferentes do conflito. Uma dinâmica multinível semelhante acontece com os agentes naturais vivos, sendo que, em vez de articulações locais, regionais, nacionais ou globais, se articulam nas distintas escalas de organismo, população, habitat, ecossistema, bioma, continente e planeta, que exibem relações interescalares tais como migrações intercontinentais, catástrofes climáticas e mudanças bruscas de paisagem. 
Na tentativa de tratar essa complexidade de relações transníveis entre atores sociais, atores naturais e entre si, lanço mão do conceito de escalas fractais, no qual esses relacionamentos mostram conexões auto-semelhantes, porém irregulares, como acontece em objetos geométricos (Briggs, 1992). O uso da analogia fractal ajuda o etnógrafo a se afastar de abordagens sistêmicas, nas quais cada nível é hierárquica e funcionalmente encaixado em outro, e de sair de abordagens neomarxistas, nas quais os níveis superiores controlam e determinam o que sucede nos níveis inferiores, para dar conta da maneira sui generis com que fatores contingentes se combinam com fatores estruturantes. O etnógrafo de conflitos socioambientais tem a responsabilidade de identificar e mapear essas múltiplas conexões fractais. Embora essa tarefa guarde uma afinidade com o que Marcus (1995) nomeou "etnografia multissítio” onde o etnógrafo segue um grupo social nas suas manifestações culturais em distintas partes do mundo, há uma diferença básica: a delimitação de etnografia multissítio é dada pelo grupo social sendo estudado, enquanto que, no caso de uma etnografia multiator, essa delimitação é dada pela dinâmica do conflito em si. Em resumo, os desafios para a ecologia política consistem, pelo menos, em identificar os distintos níveis em que os atores sociais e naturais funcionam e descrever a maneira com que se inter-relacionam transversalmente no complexo processo de luta sociopolítica e ambiental.

\section{Onivel estratégico da região}

Apesar do fato de que os múltiplos atores sociais e naturais funcionem em distintos níveis, para analisar etnograficamente um conflito socioambiental alguma delimitação biogeográfica é necessária. O etnógrafo pode escolher qualquer nível para essa delimitação - local, regional, nacional, global - e desde esse nível mapear os conexões transníveis fractais superiores e inferiores que os atores desenvolvem. Para nossos fins, gostaria de resgatar o nível intermediário da "região" como uma delimitação estratégica para explorar essas relações que oferece insights que não necessariamente apareceriam em estudos que privilegiam outros níveis.

Os historiadores ambientais têm usado com sucesso delimitações regionais baseadas em biomas, como é o caso da Mata Atlântica no Brasil (Dean, 1995) ou da Pradaria Grande nos Estados Unidos e Canadá (Worster, 1979). Estudos sobre a Amazônia fazem delimitações biogeográficas utilizando bacias 
hidrográficas, que também mostram dinâmicas escalares fractais (Little, 2001). Uma bacia hidrográfica é simultaneamente uma entidade geográfica que contêm distintos ecossistemas, uma área onde diversos grupos sociais, com suas respectivas instituições socioeconômicas, constroem um modo de vida particular e o locus para mobilização política e ambiental em torno do conflito socioambiental. Outra forma ainda de delimitação biogeográfica reside no conceito de Bennett (1969) de "região socionatural”, definido como

um sistema no qual grupos humanos diversos adaptam em maneiras padronizadas aos recursos vegetais, animais e ambientais, entre si, às forças hierárquicas administrativas e do mercado e aos grupos de pressão política e outras formas de organização sociopolítica. (Smith; Reeves, 1989, p. 14, tradução minha).

\section{Múltiplas escalas temporais}

A abordagem da ecologia política requer a ampliação do marco temporal da pesquisa para tratar as temporalidades geológicas (expressas em bilhões de anos), biológicas (expressas em milhões de anos) e sociais (expressas em milhares de anos) de forma conjunta. Nesse processo, o conceito de paisagem é de muita utilidade, já que tem dimensões humanas e biofísicas e registra mudanças climáticas, vegetacionais, faunísticas ou oceânicas, mas que somente se tornam visíveis depois de um longo período de tempo. A combinação dialética dos processos sociais e naturais produz uma dinâmica histórica única que está sendo estudada sistematicamente pelo campo de pesquisa da ecologia histórica (Balée, 1998; Crumley, 1994).

Para entender mudanças na paisagem, o ecólogo político pode empregar a historiografia de "longa duração", desenvolvida pelos historiadores franceses a partir dos anos 1920 e posteriormente expandida por Fernand Braudel (1976). O campo de pesquisa da história ambiental representa uma tentativa recente de incorporar as temporalidades do mundo biofísico dentro da análise da história humana. Dessa forma, os historiadores, que antes se limitavam a tratar a história social, e os geólogos e biólogos, que reconstruíam a história natural de um lugar, combinam seus enfoques dentro do paradigma ecológico na procura de entender as mudanças de longa duração na paisagem com base na análise das distintas ondas de ocupação humana e seus respectivos impactos socioambientais. 


\section{Os usos da ecologia política}

Uma vez delineados os desafios teóricos e metodológicos da variante etnográfica da ecologia política, cabe fazer uma breve reflexão sobre sua prática e seus usos na sociedade em geral. No intuito de esclarecer o papel que o etnógrafo ocupa no conflito, parto da noção que ele ou ela é um ator social que participa ativamente nos conflitos, porém com um papel diferenciado dos demais atores. No processo de pesquisa, equipado com um conjunto de ferramentas analíticas e comunicativas refinadas, o etnógrafo gera conhecimento estratégico que incorpora múltiplos pontos de vista. Em alguns casos, o etnógrafo tem informação a que nenhum dos outros atores sociais tem acesso, o que lhe dá uma cota específica de poder no cenário político do conflito.

Para o etnógrafo não há um lugar indefinido fora do conflito, onde possa ter uma visão "imparcial” do conflito. Pelo contrário, se situa intencionalmente nos interstícios do conflito para indagar sobre a natureza das conexões entre os grupos em conflito e constrói seu próprio lugar para produzir conhecimento socioambiental sobre o conflito. Sua meta consiste em realizar uma análise ecológica do conflito que: 1) identifica e diferencia os variados agentes socioambientais envolvidos; 2) incorpora seus múltiplos pontos de vista e interesses; 3) mapeia suas relações transníveis; e 4) documenta etnograficamente a história do conflito, com suas alianças políticas ad hoc, suas acomodações mútuas, suas negociações e suas rupturas políticas.

A mesma escolha de "etnografar" um conflito determinado representa uma decisão política e, no processo, transforma um problema social num tema de análise científica. Na exploração das implicações conceituais de problemas sociais, a pesquisa na ecologia política não somente contribui para sua compreensão, mas "visibiliza” atores socioambientais marginalizados e revela conexões e relações de poder antes ignoradas. Esse conhecimento, por sua vez, contém o potencial de ser apropriado pelos próprios atores sociais e pode provocar um questionamento de políticas públicas vigentes e propostas de novos tipos de ação e controle público.

Na apresentação dos diversos grupos sociais, o etnógrafo dá ênfase a suas respectivas reivindicações e às bases internas e externas da sua legitimação. Em muitos casos, isso lhe leva a dedicar particular atenção aos grupos marginalizados ou fantasmagóricos. A identificação dos direitos em conflito cumpre a função de ampliar o debate político para incluir direitos culturais ou sociais ignorados pelo 
Estado ou por atores hegemônicos. Dessa forma, os discursos tanto hegemônicos quanto contra-hegemônicos e a relação entre eles ganham destaque.

A etnografia dos conflitos socioambientais levanta questões éticas sobre a pesquisa em si. O etnógrafo tem que tomar muito cuidado que a informação que publica não seja empregada diretamente contra os interesses da pessoa ou grupo do qual a informação foi levantada. Embora o investigador nunca controle completamente o conhecimento que produz uma vez que entre na esfera pública, seu entendimento dos diferenciais de poder e da dinâmica histórica do conflito pode servir como orientações básicas para o manejo do conhecimento produzido. Ao mesmo tempo, ao dar tratamento etnográfico a múltiplos grupos, precisa tomar cuidado de apresentar tanto os atributos e reivindicações quanto as falhas e manobras de cada grupo e assim evitar a tendência de ocultar dados “desfavoráveis” a seu grupo preferido. Só assim o pesquisador pode mostrar que é um interlocutor honesto e aberto.

A descrição e análise de casos de degradação ou destruição socioambiental, com seus respectivos impactos sociais e ambientais, serve para ampliar os debates para além de considerações estritamente sociais ou políticas. Em muitos casos, o etnógrafo se apóia em análises quantitativas e qualitativas feitas por cientistas naturais sobre fenômenos como o esgotamento de depósitos petrolíferos, a destruição dos habitats de populações vegetacionais e faunísticas, mudanças no regime pluvial, erosão dos solos e contaminação do ar, água e terra. A integração de antropólogos em equipes transdisciplinares serve para incorporar no estudo os impactos socioculturais das mudanças biofísicas e, assim, ampliar o entendimento do conflito.

O conhecimento gerado pela pesquisa em ecologia política pode também servir como subsídio para a formulação e implementação das políticas públicas que levam em conta as reivindicações dos grupos sociais em conflito. Ao levantar aspectos ocultos ou latentes do conflito e dar visibilidade a grupos marginalizados, o antropólogo pode contribuir para uma eventual resolução do conflito. E, na medida em que tenha ganhado a confiança dos principais atores envolvidos no conflito, o pesquisador ocupa um lugar privilegiado para a mediação entre os atores.

O tratamento acadêmico, crítico e público dos assuntos presentes nos conflitos socioambientais abre a possibilidade de que os ecólogos políticos elaborem sua própria agenda, que privilegia a produção e disseminação de conhecimento confiável, holístico e estratégico sobre esses conflitos. São elementos da "política" da prática de ecologia política. 


\section{Referências}

BALÉE, William. Advances in historical ecology. New York: Columbia University Press, 1998.

BARNES, Barry; BLOOR, David. Relativism, rationalism and the sociology of knowledge. In: HOLLIS, M.; LUKES, S. (Ed.). Rationalism and relativism. Cambridge: MIT Press, 1982. p. 21-47

BATESON, Gregory. Steps to an ecology of mind. New York: Ballantine, 1972.

BENNETT, John W. Northern plainsmen: adaptive strategy and agrarian life. Chicago: Aldine Publishing, 1969.

BENNETT, John W. The ecological transition: cultural anthropology and human adaptation. New York: Pergamon Press, 1976.

BENNETT, John W. Human ecology as human behavior: essays in environmental and development anthropology. New Brunswick: Transaction, 1993. BRAMWELL, Anna. Ecology in the $20^{\text {th }}$ century: a history. New York: Yale University Press, 1989.

BRAUDEL, Fernand. História e ciências sociais. Lisboa: Presença, 1976.

BRIGGS, John. Fractals: the patterns of chaos. New York: Simon and Schuster, 1992.

CONKLIN, Harold C. An ethnoecological approach to shifting agriculture. Transactions of the New York Academy of Sciences, v. 17, n. 2, p.133-142, 1954. CRUMLEY, Carole L. (Ed.). Historical ecology: cultural knowledge and changing landscapes. Santa Fe: School of American Research Press, 1994.

DASMANN, Raymond F. National parks, nature conservation, and "future primitive”. In: BODLEY, J. H. (Ed.). Tribal people and development issues: a global overview. Mountain View: Mayfield Publishing Company, 1988. p. 301-310.

DEAN, Warren. With broadax and firebrand: the destruction of the Brazilian Atlantic Forest. Berkeley: University of California Press,1995.

DIAMOND, Jared. Guns, germs and steel: the fates of human societies. New York: W. W. Norton, 1997. 
DICIONÁRIO eletrônico Houaiss da língua portuguesa. Versão 1.05. Editora Objetiva, 2004. 1 CD-ROM.

EMANUEL, Robert M.; GREENBERG, James B. Lluvia enojada Tyoo Nasi: the political ecology of forest extraction in the Sierra Chatina, Oaxaca. Paper apresentado na Reunião da Sociedade de Antropologia Aplicada, Tucson, AZ, 1999. GIDDENS, Anthony. The consequences of modernity. Stanford: Stanford University Press, 1990.

GOODMAN, Alan H.; LEATHERMAN, Thomas L.(Ed.). Building a new biocultural synthesis: political-economic perspectives on human biology. Ann Arbor: University of Michigan Press, 1998.

HARAWAY, Donna. Situated knowledges: the science question in feminism and the privilege of partial perspective. Feminist Studies, v. 14, n. 3, p. 575600, 1988.

HARAWAY, Donna. When man is on the menu. In: CRARY, J.; KWINTER, S. (Ed.). Incorporations. New York: Urzone, 1992. p. 39-44.

HAWLEY, Amos H. Human ecology: a theory of community structure. New York: Ronald, 1950.

HOLLING, C. S.; SANDERSON, Steven. Dynamics of (dis)harmony in ecological and social systems. In: HANNA, S. S.; FOLKE, C.; MÄLER, K. (Ed.). Rights to nature. Washington: Island Press, 1996. p. 57-85.

KAUFFMAN, Stuart A. Antichaos and adaptation. Scientific American, v. 265, p. 78-84, August 1991.

KINSLEY, David. Ecology and religion: ecological spirituality in cross-cultural perspective. Englewood Cliffs: Prentice-Hall, 1995.

KUEHLS, Thom. Beyond sovereign territory. Minneapolis: University of Minnesota Press, 1996.

LATOUR, Bruno. Políticas da natureza: como fazer ciência na democracia. Tradução de C. A. Mota de Souza. São Paulo: Eduscs, 2004.

LAW, John. Technology and heterogeneous engineering: the case of Portuguese expansion. In: BIJKER, W. E.; HUGHES, T. P.; PINCH, T. (Ed.). The social construction of technological systems. Cambridge: MIT Press, 1987. p. 111-134.

LEVINS, Richard; LEWONTIN, Richard. The dialectical biologist. Cambridge: Harvard University Press, 1985. 
LITTLE, Paul E. Ecología política del Cuyabeno: el desarrollo no sostenible de la Amazonía. Quito: Ildis: Abya-Yala, 1992.

LITTLE, Paul E. Environments and environmentalisms in anthropological research: facing a new millennium. Annual Review of Anthropology, v. 28, p. 253-284, 1999a.

LITTLE, Paul E. Political ecology as ethnography: the case of Ecuador's Aguarico River Basin. Brasília: Departmento de Antropologia, Universidade de Brasília, 1999b. (Série Antropologia, n. 258).

LITTLE, Paul E. Amazonia: territorial disputes on perennial frontiers. Baltimore: Johns Hopkins University Press, 2001.

LITTLE, Paul E. The political ecology of Amazon floodplain fisheries. In: IMBERGER, J.; GAYNOR, A.; LEYBOURNE, M.; TOUSSAINT, S. (Ed.). Water: histories, cultures, ecologies. Perth: University of Western Australia Press, 2006. p. 192-204.

MARCUS, George E. Ethnography in/of the world system: the emergence of multi-sited ethnography. Annual Review of Anthropology, v. 24, p. 95-117, 1995.

MELTZOFF, Sara K.; LICHTENSZTAJN, Yair G. Climate changes in Pisagua, Chile: renovating a natural prison amidst fishermen, political ghosts, and tourists. Paper apresentado na Reunião da Sociedade de Antropologia Aplicada, Tucson, AZ., 1999.

MERCHANT, Carolyn. Ecological revolutions: nature, gender, and science in New England. Chapel Hill: University of North Carolina Press, 1989.

MORAN, Emilio F. (Ed.). The ecosystem approach in anthropology: from concept to practice. Ann Arbor: University of Michigan Press, 1990.

RABINOW, Paul. Artificiality and enlightenment: from sociobiology to biosociality. In: CRARY, J.; KWINTER, S. (Ed.). Incorporations. New York: Urzone, 1992. p. 234-252.

RAPPAPORT, Roy. Pigs for the ancestors. New Haven: Yale University Press, 1968.

RIBEIRO, Gustavo Lins; LITTLE, Paul E. Neoliberal recipes, environmental cooks: the transformation of Amazonian agency. In: PHILLIPS, L. (Ed.). The third wave of modernization in Latin America: cultural perspectives on neoliberalism. Wilmington: SR Books, 1998. p. 175-191. 
ROOSEVELT, Anna C. Determinismo ecológico na interpretação do desenvolvimento social indígena da Amazônia. In: NEVES, W. A. (Comp.). Origens, adaptações e diversidade biológica do homem nativo da Amazônia. Belém: MPEG: SCT: CNPq: PR, 1991. p. 103-142.

SCHMINK, Marianne; WOOD, Charles H. The "political ecology" of Amazonia. In: LITTLE, P. D.; HOROWITZ, M. M.; NYERGES, E. (Ed.). Lands and risk in the Third World. Boulder: Westview Press, 1987. p. 38-191.

SHERIDAN, Thomas E. Where the dove calls: the political ecology of a peasant corporate community in northwestern Mexico. Arizona: The University of Arizona Press, 1988.

SMITH, Sheldon; REEVES, E. Introduction. In: SMITH, Sheldon; REEVES, E. (Ed.). Human systems ecology: studies in the integration of political economy, adaptation, and socionatural regions. Boulder: Westview, 1989. p. 1-18.

STEWARD, Julian H. Basin-Plateau aboriginal sociopolitical groups. Bulletin 120. Washington: Smithsonian Institute, Bureau of American Ethnology, 1938.

STEWARD, Julian H. Theory of culture change. Urbana: University of Illinois Press, 1955.

STONICH, Susan. "I am destroying the land!" The political ecology of poverty and environmental destruction in Honduras. Boulder: Westview Press, 1993.

VAYDA, Andrew P.; WALTERS, Bradley B. Against political ecology. Human Ecology, v. 27, n. 1, p. 167-179, 1999.

WALDROP, M. Mitchell. Complexity: the emerging science at the edge of order and chaos. New York: Simon and Schuster, 1992.

WORSTER, Donald. Dust Bowl: the southern plains in the 1930s. New York: Oxford University Press, 1979.

WORSTER, Donald. The wealth of nature: environmental history and the ecological imagination. New York: Oxford University Press, 1993. 